\title{
Rare desmoplastic trichilemmoma associated with sebaceous nevus ${ }^{*}$
}

\author{
Márcio Martins Lobo Jardim ${ }^{1}$ \\ Renata Cavanellas Fraga ${ }^{2}$
}

\author{
Bruno de Castro e Souza ${ }^{1}$ \\ Rafael Cavanellas Fraga ${ }^{3}$
}

DOI: http:/ / dx.doi.org/10.1590/abd1806-4841.20176540

\begin{abstract}
Nevus sebaceous of Jadassohn is a congenital hamartoma that usually affects the scalp and face. Several benign or malignant neoplasias may develop in the lesion and the most common are trichoblastoma, syringocystadenoma papilliferum, and basal cell carcinoma. Trichilemmoma is a benign solid tumor originating from external sheath cells of pilosebaceous follicles. When it is characterized by a central zone of desmoplasia, it is called desmoplastic trichilemmoma. We report a case of a 58-year-old patient who developed a tumor in a sebaceous nevus. We performed a total excision of the lesion. Histopathological diagnosis was compatible with desmoplastic trichilemmoma. Our literature review reveals that the occurrence of trichilemmoma desmoplastic is unusual. Moreover, it can mimic an invasive carcinoma on histological and clinical examinations. This fact confirms the importance of reporting the occurrence of this rare cancer in a nevus sebaceous of Jadassohn.
\end{abstract}

Keywords: Nevus Sebaceous of Jadassohn; Neoplasms; Pediatrics

\section{INTRODUCTION}

Nevus sebaceous of Jadassohn (NS) is a congenital cutaneous hamartoma composed of epidermal, dermal, follicular, and apocrine appendages. ${ }^{1}$ It may be present at birth or develop in childhood, typically as a yellowish plaque, more commonly located on the scalp or face. ${ }^{2}$

The development of both benign and malignant neoplasias in a NS has been described. The most common tumors described are trichoblastoma, syringocystadenoma papilliferum, and basal cell carcinoma. ${ }^{2}$ However, less prevalent neoplasms, such as sebaceoma and trichilemmoma, have also been described.

Trichilemmoma is a benign solid tumor originating from external sheath cells of pilosebaceous follicles. We report the case of a patient who developed a desmoplastic trichilemmoma (which is a rare histological variant of trichilemmoma) in a NS.

\section{CASE REPORT}

A 58-year-old female patient without comorbidities and with a history of smoking (30 packs/year) reported a lesion on the scalp present since childhood, which grew during adolescence and remained stable until 2014. Two years ago, an asymptomatic erythematous nodule with pearly keratotic borders appeared in the lesion. The patient reported no use of medications. Dermatological examination revealed a $7 \times 3 \mathrm{~cm}$ yellowish plaque in the left parietal region of the scalp, with a
$1.5 \mathrm{~cm}$ erythematous and keratotic nodule arising from the lesion (Figure 1). Our diagnostic hypotheses included trichoblastoma, basal cell carcinoma, and syringocystadenoma papilliferum. The nodule was excised and sent for histopathological analysis, which resulted in a diagnosis of desmoplastic trichilemmoma (Figures 2 and 3).

\section{DISCUSSION}

NS was first described by the dermatologist Josef Jadassohn in 1895. It is a congenital cutaneous hamartoma comprising of epidermal, dermal, follicular, and apocrine appendages. ${ }^{1}$ It is usually present at birth or occur early in childhood, but it may not be apparent until the patient is older. ${ }^{1}$

NS most commonly affects the face and scalp. The lesions typically appear as solitary yellowish plaques, in an oval or linear patch of alopecia. ${ }^{3}$ Less common sites of involvement include the trunk, neck, and oral mucosa. ${ }^{3}$

Clinically, NS develops in three distinct phases. The first occurs in childhood and is characterized by papillomatous hyperplasia and immature hair follicles. The second phase begins with the onset of puberty, under the influence of sex hormones. It is marked by a rapid increase in the size of the lesion, which acquires a verrucous appearance. This proliferation, in a histological view, occurs due to a hyperplasia of the sebaceous glands and epidermis and due to

\section{Received on 28.09.2016.}

Approved by the Advisory Board and accepted for publication on 26.12.2016.

Work carried out in the Alopecia Outpatient Clinic at the Hospital Naval Marcílio Dias (HNMD), Rio de Janeiro, RJ, Brazil.

Financial support: none.

Conflict of interest: none.

Dermatology Department at Hospital do Servidor Público Estadual de São Paulo - São Paulo (SP), Brazil

Medical Student at Escola Superior de Ciências da Santa Casa de Misericórdia de Vitória (EMESCAM-ES) - Vitória (ES), Brazil

Private Clinic - São Paulo (SP), Brazil

@2017 by Anais Brasileiros de Dermatologia 


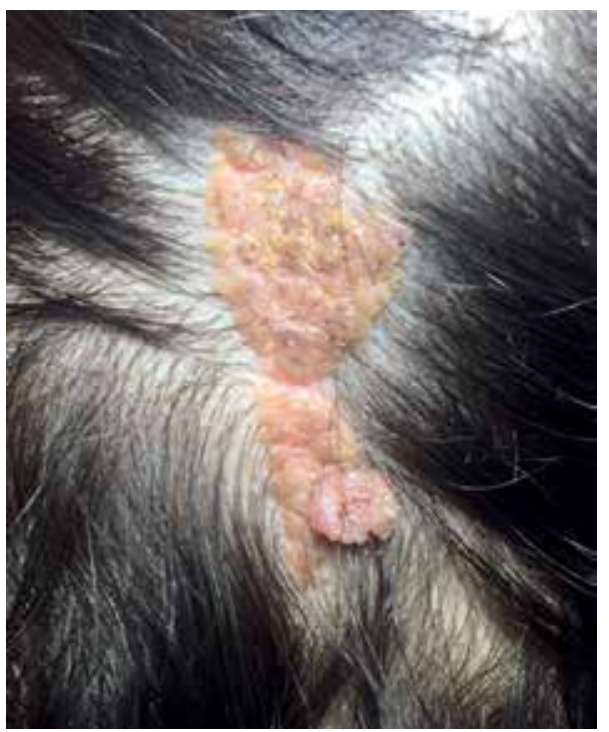

Figure 1: Erythematous and keratotic nodule arising from the nevus sebaceous

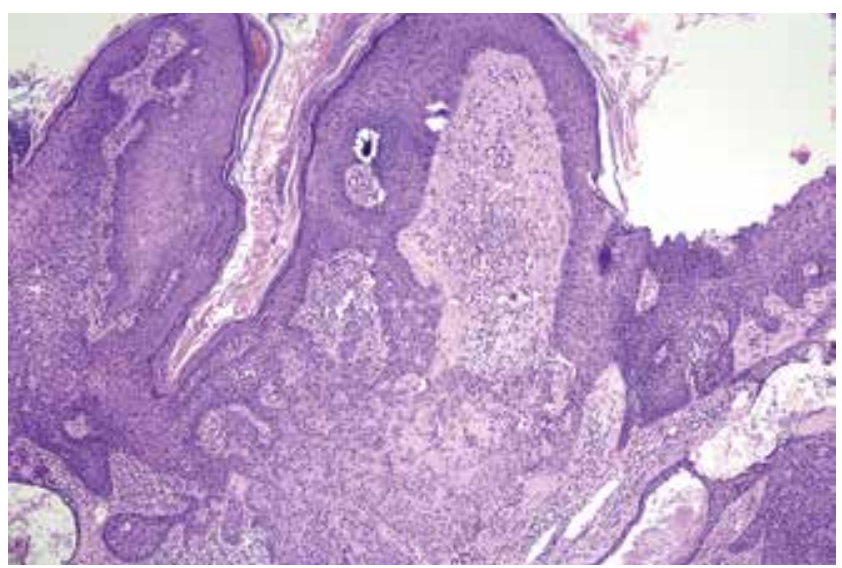

Figure 2: Proliferation of cells with clear cytoplasm in the midst of epidermal hyperplasia (Hematoxylin \& eosin, X40)

the maturation of the apocrine glands. ${ }^{3}$ In the third and final stage, benign or malignant neoplasms appear on the NS. Trichoblastoma, syringocystadenoma papilliferum, and basal cell carcinoma are the most common tumors seen. ${ }^{2}$ However, less prevalent neoplasms, such as sebaceoma and trichilemmoma, have also been described.

Trichilemmoma is a benign solid tumor originating from

\section{REFERENCES}

1. Kamyab-Hesari K, Seirafi H, Jahan S, Aghazadeh N, Hejazi P, Azizpour A, et al. Nevus sebaceus: a clinicopathological study of 168 cases and review of the literature. Int J Dermatol. 2016;55:193-200

2. Baykal C, Buyukbabani N, Yazganoglu KD, Saglik E. Tumors associated with nevus sebaceous. J Dtsch Dermatol Ges. 2006:4:28-31.

3. Moody MN, Landau JM, Goldberg LH. Nevus Sebaceous Revisited. Pediatr Dermatol. 2012;29:15-23.

4. Idriss MH, Elston DM. Secondary neoplasms associated with nevus sebaceus of Jadassohn: a study of 707 cases. J Am Acad Dermatol. 2014;70:332-7.

5. Dore E, Noe MH, Swick BL. Trichoblastoma, syringocystadenoma papilliferum, desmoplastic trichilemmoma and tumor of the follicular infundibulum with signetring cells, all arising in nevus sebaceus. J Cutan Pathol. 2015;42:645-51.

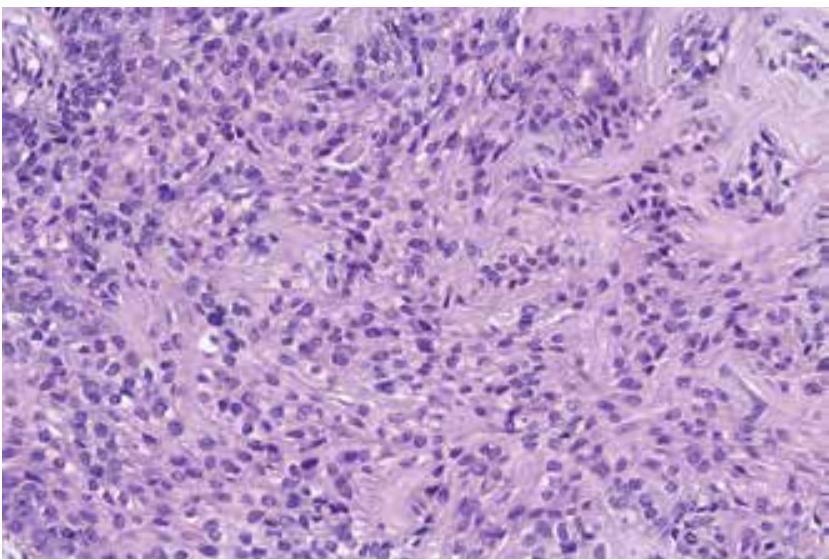

FIGURE 3: Cytoarchitectural features of the neoplasia: cells exhibiting trichilemal differentiation in a desmoplastic stroma (Hematoxylin \& eosin, X400)

external sheath cells of pilosebaceous follicles. When it is characterized by a central zone of desmoplasia, it is called desmoplastic trichilemmoma. Despite its benign nature, desmoplastic trichilemmoma is a tumor that can clinically present itself as a pearly and sometimes ulcerated lesion that may clinically mimic an invasive carcinoma. ${ }^{4}$ Our patient presented with a pearly erythematous nodule, which led to a diagnostic hypothesis of basal cell carcinoma.

The occurrence of a trichilemmoma in a lesion of NS is well reported in the literature. However, only a few cases report a nevus sebaceous associated with the appearance of a trichilemmoma in its desmoplastic variant. In a study series of 707 cases of nevus sebaceous published in 2013, Idriss \& Elston found only three patients ( $2 \%$ of the total sample) who presented with desmoplastic trichilemmoma, confirming the rarity of the present case. ${ }^{4}$

In 2015, Dore et al. published a case in which a patient developed four papules on the surface of a long-standing nevus sebaceous on the scalp. After surgical excision of the lesion, histopathological examination revealed four distinct tumors: trichoblastoma, syringocystadenoma papilliferum, desmoplastic trichilemmoma, and tumor of the follicular infundibulum. ${ }^{5}$

Because it is a benign tumor, the removal of desmoplastic trichilemmoma is not usually indicated. However, since it is a rare cutaneous tumor, easily confused with other invasive cutaneous neoplasms, complete surgical excision of the lesion is required in order to confirm the diagnosis by histopathological examination. $\square$

\section{MAILING ADDRESS: \\ Márcio Martins Lobo Jardim \\ Av. Ibirapuera, $981-4^{\circ}$ andar \\ Indianópolis \\ 60747-318 São Paulo, SP - Brazil \\ E-mail:martinslobojardim@gmail.com}

How to cite this article: Lobo-Jardim MM, Souza BC, Fraga RC, Fraga RC. Rare desmoplastic trichilemmoma associated with sebaceous nevus. An Bras Dermatol. 2017;92(6): 836-7. 